\title{
Stimulus Intensity For Measuring Temporal Summation Of Second Pain: The Case-Control Study Of Patients With Chronic Pain And Healthy Individuals
}

\section{Moriguchi Daisuke ( $\nabla$ daisukemoriguchi@dent.osaka-u.ac.jp )}

Osaka University Graduate School of Dentistry

\section{Ishigaki Shoichi}

Osaka University Graduate School of Dentistry

\section{Lin Xiaoyu}

Osaka University Graduate School of Dentistry

\section{Kuyama Kotaro}

Osaka University Graduate School of Dentistry

Koishi Yukiko

Osaka University Graduate School of Dentistry

\section{Takaoka Ryota}

Osaka University Graduate School of Dentistry

\section{Svensson Peter}

Aarhus University

\section{Yatani Hirofumi}

Osaka University Graduate School of Dentistry

\section{Research Article}

Keywords: Myofascial pain, temporal summation, temporomandibular disorders, thermal detection, central sensitization

Posted Date: March 7th, 2022

DOI: https://doi.org/10.21203/rs.3.rs-1364667/v1

License: (c) (i) This work is licensed under a Creative Commons Attribution 4.0 International License. Read Full License 


\section{Abstract}

Background: Central sensitization (CS) of the nociceptive system is linked to a disparity between the perceived pain intensity and the severity of the tissue damage in many chronic pain conditions. Temporal summation of second pain (TSSP) has been suggested as a psychophysical index for CS. However, there is no golden standard for protocols to measure TSSP. The purpose was to establish the stimulus intensity for measuring TSSP to obtain the best assessment of CS in healthy individuals and patients with chronic pain.

Methods: Women patients with chronic myofascial temporomandibular disorders pain $(n=16)$ and healthy women volunteers with no pain $(n=15)$ participated. First, TSSP response patterns in healthy volunteers with no pain were tested. Second, differences in TSSP between groups were investigated. Pain thresholds $\left(\mathrm{PT}{ }^{\circ} \mathrm{C}\right)$ were measured, and repetitive heat stimuli at three stimulus intensities $\left(\mathrm{PT}{ }^{\circ} \mathrm{C}, \mathrm{PT}+1\right.$ ${ }^{\circ} \mathrm{C}, \mathrm{PT}+2{ }^{\circ} \mathrm{C}$ ) were applied. TSSP parameters were quantified as TSSP magnitude (TSm), TSSP frequency (TSf). Generalized linear mixed-effect models with repetitive stimuli on pain ratings were conducted.

Results: In healthy women volunteers, pain ratings significantly decreased at $\mathrm{PT}{ }^{\circ} \mathrm{C}(\mathrm{P}<.050)$, besides TSm and TSf at $\mathrm{PT}+2{ }^{\circ} \mathrm{C}$ were significantly higher than those at $\mathrm{PT}{ }^{\circ} \mathrm{C}(\mathrm{P}<.025)$. In chronic pain patients, pain ratings significantly increased at $\mathrm{PT}+1^{\circ} \mathrm{C}$ and $\mathrm{PT}+2{ }^{\circ} \mathrm{C}(\mathrm{P}<.050)$. At $\mathrm{PT}+2{ }^{\circ} \mathrm{C}, \mathrm{TSm}$ and TSf in chronic pain patients were significantly higher than healthy volunteers $(P<.050)$.

Conclusion: The stimulus intensity should be individually adjusted to $2{ }^{\circ} \mathrm{C}$ above the patient's pain thresholds to assess TSSP clearly.

\section{Background}

Central sensitization (CS) is defined as "Increased responsiveness of nociceptive neurons in the central nervous system to their normal or subthreshold afferent input," by the International Association for the Study of Pain (1). CS has been proposed as one of the critical mechanisms in many chronic pain-related conditions that have a disparity between the magnitude of tissue damage and self-reported pain intensity, which cannot be readily explained $(2,3)$. CS seems essential to understand in the chronification of pain (4).

There is currently no gold standard of definitions, methods, or guidelines for diagnosing CS, so it is necessary to establish a standardized method to assess CS. Dynamic Quantitative Sensory Test (dynamic QST) could be a valuable technique to measure CS(5). This is a way to evaluate the excitability of different pain pathways/mechanisms using various stimulus modalities and quantify pain as objectively as possible(6-10). Dynamic QST can be used to measure the Temporal Summation of Second Pain (TSSP) phenomenon, which has long been proposed as an essential modality for functional evaluation of $\operatorname{CS}(2,5,11)$. Existing protocols for the measurement of TSSP usually apply a fixed stimulus intensity $(6,7)$. More recently, individualized protocols suited for within-individual monitoring have been developed $(8,12-14)$ because patients' pain thresholds are different from individual to individual(15-18). 
The earlier study applied an individual's pain thresholds $+2{ }^{\circ} \mathrm{C}$ as the stimulus intensity for the individualized protocol(14). However, there is no golden standard for protocols to set the stimulus intensity for measuring TSSP. This study's primary objective was to establish the stimulus intensity for measuring TSSP to obtain the best assessment of CS. The hypothesis was that differences between chronic pain patients and healthy participants with no pain would be observed more prominently at the pain threshold $+2{ }^{\circ} \mathrm{C}$ than at the pain threshold and the pain threshold $+1{ }^{\circ} \mathrm{C}$.

\section{Methods}

\section{Experimental Design}

The pain threshold of each participant $\left(\mathrm{PT}^{\circ} \mathrm{C}\right)$ was determined, and then TSSP was measured using three stimulus intensities $\left(\mathrm{PT}{ }^{\circ} \mathrm{C}, \mathrm{PT}+1{ }^{\circ} \mathrm{C}, \mathrm{PT}+2^{\circ} \mathrm{C}\right)$. Heat stimuli were applied to the non-dominant thenar eminence at the orientation and training session, and heat stimuli were applied to the dominant thenar eminence at the testing session.

Participants were sitting relaxed on a chair in a quiet room with a temperature of $20-24{ }^{\circ} \mathrm{C}$. The test was performed using a computerized thermal sensory stimulator (PATHWAY, Medoc Ltd, Israel) via a thermode $(30 \times 30 \mathrm{~mm}$, Advanced Thermal Stimulator model). The stimulus delivered with PATHWAY is controlled by a computer. The temperature span is from -10 to $55^{\circ} \mathrm{C}$. When the TSSP was measured, the experimental pain was rated continuously using a CoVAS (Medoc Ltd., Israel). It is an electronic visual analog scale (VAS) used to rate the pain intensity for each thermal pulse. During stimulus application, participants were asked to rate the perceived pain by moving the CoVAS slider continuously. The extreme left on the $100 \mathrm{~mm}$ CoVAS was labeled "no pain," and the extreme right was "most pain imaginable."

\section{Participants}

The sample size was calculated by setting risks for type 1 and type 2 errors of $5 \%$ and $20 \%$, respectively. Mean and standard deviation of experienced pain were obtained from the pilot study. Periods of recruitment and data collection were from April 2018 to August 2019. One hundred three consecutive participants were recruited from outpatients at the Department of Fixed Prosthodontics at Osaka University Dental Hospital and Osaka University Dental Hospital staff. The main inclusion criteria were: 1) willing to participate and give informed consent; 2) above 20 years of age. The exclusion criteria were: 1) individuals unable to communicate or follow instructions; 2 ) use of narcotics, antidepressants, and psychotropics; and 3) individuals with paralysis or a skin disorder at the hand. Out of 103 participants, a total of 16 women patients with chronic frequent primary myofascial orofacial pain or chronic highly frequent primary myofascial orofacial pain or chronic frequent primary temporomandibular joint pain or chronic highly frequent primary temporomandibular joint pain (we call them "chronic pain patients"), and 15 women healthy volunteers with no pain were identified. Flow diagrams of participants can be found in Fig. 1. They were diagnosed following the ICOP(19) and the DC / TMD(20) by two instructors from the Japanese Society for Temporomandibular Joint and the Japanese Society of Orofacial Pain. 
The inclusion criteria for women healthy volunteers with no pain were: 1 ) those with good health status with no self-reported diseases; 2) those with a global Severity Index < 68; and 3) those who had no pain for four weeks before this test (including back pain, stomach pain, pain in arms or legs, menstrual cramps, headache, chest pain, masticatory muscle pain, and temporomandibular joint pain). The history of pain was obtained using the PHQ-15(21) and the TMD Pain Screener(22).

3. Measurements of pain thresholds

1) Orientation and training session

A standard script was read for each participant before assessing the pain threshold. Heat stimuli were applied to the non-dominant thenar eminence. The starting temperature was $32{ }^{\circ} \mathrm{C}$, and then the temperature of the stimuli was changed at several ascending and descending sets of stimuli. Particular care was taken to instruct the participants and make sure they understood the measurement procedure well. All participants received training until they were familiar with the test protocol.

2) Testing session

Heat stimuli were applied to the dominant thenar eminence. Pain thresholds $\left(\mathrm{PT}{ }^{\circ} \mathrm{C}\right)$ were measured following the instructions developed by the German Research Network on Neuropathic Pain (DFNS). All thresholds were obtained with ramped stimuli $\left(1^{\circ} \mathrm{C} / \mathrm{s}\right)$ terminated when the participant pressed a button. During the experiment, the participants were not able to watch the computer screen.

\section{Measurements of TSSP}

1) Orientation and training session

Again, a standard script was read to each participant, which defined the VAS scale and instructed each participant to rate the slow, burning sensation from each pulse (second pain), not the prickly sensation immediately felt at the delivery of each pulse (first pain). We alerted participants to expect a delay between the delivery of each pulse and the perception of the second pain.

Heat stimuli were applied to the non-dominant thenar eminence, while participants rated the experimental pain using the CoVAS with the other hand. Ten consecutive heat stimuli at $\mathrm{PT}{ }^{\circ} \mathrm{C}$ with an interstimulus interval of 2-sec were applied. As for the instructions, particular care was taken to ensure that participants understood the measurement procedure well, and they had training repeatedly until the TSSP protocol was familiar to them.

2) Testing session

Heat stimuli were applied to the dominant thenar eminence, while participants rated the experimental pain using the CoVAS with the other hand. Ten consecutive heat stimuli with an interstimulus interval of 2-sec at three stimulus intensities (randomized; $\mathrm{PT}{ }^{\circ} \mathrm{C}, \mathrm{PT}+1{ }^{\circ} \mathrm{C}, \mathrm{PT}+2{ }^{\circ} \mathrm{C}$ ) were applied. Participants had 
a five minuites break between each trial to avoid any after-sensations or ongoing pain before the subsequent trial. The measurement was blinded for examiners.

\section{Calculations of TSSP parameters}

Pain Intensity $\left(\mathrm{PI}_{\mathrm{n}}\right)$ was calculated by integrating the values of pain ratings from the peak of the temperature at the $n^{\text {th }}$ stimulus to the peak of the temperature at the $n+1^{\text {th }}$ stimulus. TSSP parameters (TSSP magnitude, TSSP frequency) were calculated using the PI and defined as follows.

TSSP magnitude (TSm): $\mathrm{PI}_{\max }-\mathrm{PI}_{1}(\mathrm{VAS} \times \mathrm{sec})$

TSSP frequency (TSf): Numbers of times $\mathrm{P}_{\mathrm{n}+1}>\mathrm{PI}_{\mathrm{n}}$ (times)

\section{Assessments of biopsychosocial functions}

1) Recent pain variables

Jaw pain was assessed with a visual analog scale. Somatic symptoms were assessed with the (21). The illness period (month) was assessed as the with pain before this test.

2) Psychological variables

Patient Health Questionnaire-15 (PHQ-15)Past pain experiences and negative thoughts or feelings about pain were assessed with the Pain Catastrophizing Scale (PCS) (23). The self-efficacy belief in individuals with pain was assessed with the Pain Self-Efficacy Questionnaire (PSEQ) (24). Somatization (SOM), Obsessive-Compulsive (O-C), Anxiety (ANX), Depression (DEP) were assessed with the T-scores of Symptom Checklist-90-Revised (SCL-90R) $(25,26)$.

7. Data reductions and Statistical methods

1) TSSP in healthy people with no pain $(n=15)$

a) Demonstrate TSSP response patterns at each stimulus intensity

Generalized Linear Mixed Models were conducted to examine the effect of repetitive stimuli on PI. The number of stimuli and age were used as covariates. $\log (\mathrm{PI}+1)$ was used as the dependent variable. The variable conversion was performed using log because PI did not have a normal distribution. The significance level was set at $a=.050$.

b) Differences in TSSP parameters across stimulus intensities

Wilcoxon signed-rank test was conducted to examine the differences in TSm and TSf between $\mathrm{PT}{ }^{\circ} \mathrm{C}$ and $\mathrm{PT}+1{ }^{\circ} \mathrm{C}, \mathrm{PT}+1{ }^{\circ} \mathrm{C}$ and $\mathrm{PT}+2{ }^{\circ} \mathrm{C}$. The significance level corrected with Bonferroni procedures was set at $\mathrm{a}=$ .025 . 
2) TSSP in patients with chronic pain patients

Healthy volunteers with no pain $(n=15)$ and chronic pain patients $(n=16)$ were selected.

a) Demonstrate TSSP response patterns in chronic pain patients

Generalized Linear Mixed Models were conducted to examine the effect of repetitive stimuli on PI. The number of stimuli and age were used as covariates. $\log (\mathrm{PI}+1)$ was used as the dependent variable. The significance level was set at $a=.050$.

b) Differences in TSSP parameters between chronic pain patients and healthy volunteers with no pain Mann-Whitney's $U$ test was conducted to examine the differences in TSm and TSf between groups. The significance level was set at $a=.050$.

\section{Results}

Descriptive data can be found in Table 1. Overall, significant group differences were found for age, pain thresholds, PHQ-15, illness period, SOM, O-C, DEP, ANX, PCS (all P<.050, the details of P values were as Table 1). 
Table 1

Descriptive data of participants.

\begin{tabular}{|c|c|c|c|}
\hline & $\begin{array}{l}\text { Healthy volunteers with no pain } \\
n=15\end{array}$ & $\begin{array}{l}\text { Chronic pain patients } \\
n=16\end{array}$ & P-values \\
\hline Age & $27 \pm 2.6$ & $51 \pm 13$ & $<.001$ \\
\hline Pain thresholds $\left({ }^{\circ} \mathrm{C}\right)$ & $47 \pm 1.0$ & $48 \pm 1.2$ & .045 \\
\hline Jaw pain $(0-100)$ & $0.00 \pm 0.00$ & $51 \pm 19$ & - \\
\hline PHQ-15 (0-30) & $0.20 \pm 0.56$ & $7.8 \pm 5.4$ & $<.001$ \\
\hline Illness period (month) & $0.00 \pm 0.00$ & $21 \pm 53$ & $<.001$ \\
\hline $\operatorname{SOM}(0-100)$ & $40 \pm 7.5$ & $60 \pm 8.3$ & $<.001$ \\
\hline O-C (0-100) & $48 \pm 9.4$ & $59 \pm 7.8$ & .002 \\
\hline $\operatorname{DEP}(0-100)$ & $43 \pm 8.5$ & $59 \pm 8.0$ & $<.001$ \\
\hline ANX $(0-100)$ & $39 \pm 4.9$ & $51 \pm 12$ & .001 \\
\hline PCS (0-52) & $6.4 \pm 8.6$ & $24 \pm 12$ & $<.001$ \\
\hline PSEQ (0-60) & $42 \pm 9.6$ & $31 \pm 17$ & .049 \\
\hline
\end{tabular}

1. TSSP in healthy volunteers with no pain

1) TSSP response patterns at each stimulus intensity

At $\mathrm{PT}{ }^{\circ} \mathrm{C}, \mathrm{Pl}_{4-8}$ was significantly lower than $\mathrm{Pl}_{1}(\mathrm{P}<.050$, the details of $\mathrm{P}$ values were as Fig. 1$)$. At $\mathrm{PT}+$ $1^{\circ} \mathrm{C}$ and $\mathrm{PT}+2^{\circ} \mathrm{C}, \mathrm{Pl}_{2-9}$ did not change significantly compared to $\mathrm{Pl}_{1}(\mathrm{P}>.050$, the details of $\mathrm{P}$ values were as Fig. 2).

2) Differences in TSSP parameters across stimulus intensities

TSm and TSf at $\mathrm{PT}+2^{\circ} \mathrm{C}$ were significantly higher than at $\mathrm{PT}{ }^{\circ} \mathrm{C}$ (P value was .021 and .011 , respectively) (Table 2). There were no significant differences between PT ${ }^{\circ} \mathrm{C}$ and $\mathrm{PT}+1^{\circ} \mathrm{C}$ in TSm and TSf (P value was .075 and .066 , respectively). 
Table 2

Outcome data of TSSP parameters in Healthy volunteers with no pain and Chronic pain patients.

\begin{tabular}{|c|c|c|c|c|c|c|}
\hline & \multicolumn{3}{|c|}{ Healthy volunteers with no pain $n=15$} & \multicolumn{3}{|c|}{ Chronic pain patients $n=16$} \\
\hline & $\mathrm{PT}{ }^{\circ} \mathrm{C}$ & $\mathrm{PT}+1{ }^{\circ} \mathrm{C}$ & $\mathrm{PT}+2{ }^{\circ} \mathrm{C}$ & $\mathrm{PT}{ }^{\circ} \mathrm{C}$ & $\mathrm{PT}+1{ }^{\circ} \mathrm{C}$ & $\mathrm{PT}+2^{\circ} \mathrm{C}$ \\
\hline TSm & $0.23 \pm 0.74$ & $4.6 \pm 9.2$ & $14 \pm 24$ & $15 \pm 37$ & $19 \pm 33$ & $49 \pm 63$ \\
\hline TSf & $0.40 \pm 1.1$ & $1.1 \pm 1.9$ & $1.9 \pm 2.1$ & $1.2 \pm 1.5$ & $2.0 \pm 2.6$ & $3.9 \pm 2.3$ \\
\hline
\end{tabular}

TSm: $\mathrm{PI}_{\max }-\mathrm{PI}_{1}(\mathrm{VAS} \times \mathrm{sec})$

TSf: Numbers of times $\mathrm{P}_{\mathrm{n}+1}>\mathrm{PI}_{\mathrm{n}}$ (times)

2. TSSP in chronic pain patients

1) TSSP response patterns in chronic pain patients

At $\mathrm{PT}{ }^{\circ} \mathrm{C}, \mathrm{Pl}_{2-9}$ did not change significantly compared to $\mathrm{PI}_{1}(\mathrm{P}>.050$, the details of $\mathrm{P}$ values were as Fig. 3). At $\mathrm{PT}+1^{\circ} \mathrm{C}, \mathrm{Pl}_{4-9}$ was significantly higher than $\mathrm{PI}_{1}(\mathrm{P}<.050$, the details of $\mathrm{P}$ values were as Fig. 3). At $\mathrm{PT}+2^{\circ} \mathrm{C}, \mathrm{Pl}_{3-9}$ was significantly higher than $\mathrm{PI}_{1}(\mathrm{P}<.050$, the details of $\mathrm{P}$ values were as Fig. 3).

2) Differences in TSSP parameters between chronic pain patients and healthy volunteers with no pain

There were significantly higher TSm, TSf in chronic pain patients at PT $+2{ }^{\circ} \mathrm{C}$ ( $\mathrm{P}$ value was .041 and .027 , respectively) (Table 2). There were no significant differences by group in TSm at $\mathrm{PT}{ }^{\circ} \mathrm{C}$ and $\mathrm{PT}+1^{\circ} \mathrm{C}(\mathrm{P}$ value was .12 and .32 , respectively). Also, there were no significant differences by group in TSf at PT ${ }^{\circ} \mathrm{C}$ and $\mathrm{PT}+1^{\circ} \mathrm{C}$ ( $\mathrm{P}$ value was .20 and .42 , respectively).

\section{Discussion}

The present study tested TSSP protocols in healthy individuals with no pain and chronic pain patients and identified a practical clinical paradigm to set the stimulus intensity to assess TSSP.

An individualized protocol is suited for within-individual monitoring to avoid floor and ceiling effects(8, 12-14). An earlier study applied PT $+2^{\circ} \mathrm{C}$ as the stimulus intensity to prevent floor effects(14). However, there are no studies to test differences in TSSP across stimulus intensities (PT ${ }^{\circ} \mathrm{C}, \mathrm{PT}+1^{\circ} \mathrm{C}, \mathrm{PT}+2^{\circ} \mathrm{C}$ ). It might be logical to set the stimulus intensity adjusted according to the individual pain thresholds.

TSSP refers to the increased perception of pain from repetitive, noxious stimuli $(4,5,11)$. The neurophysiological underpinnings of this phenomenon probably result from enhancements of a central 
$\mathrm{N}$-methyl-D-aspartate (NMDA) receptor mechanism within the spinal dorsal horn (brain stem) nociceptive neurons, which is termed "wind-up."(4) Wind-up has been first proposed as the increased firings of excitatory postsynaptic potential (EPSP) within the dorsal horn (brain stem) induced by repetitive electrical stimuli of peripheral C-fibers at train frequencies of more than $0.33 \mathrm{~Hz}(27)$. The pathway of input of nociceptive impulses in the trigeminal nervous system is different from that in the spinal nervous system(28). Nociceptive impulses arising from the face and oral structures are carried by the primary afferent neuron of the mandibular or maxillary division of the trigeminal nerve (V2, V3) through the Gasserian ganglion into the subnucleus caudalis region of the trigeminal spinal tract. At that point, it synapses with a second-order neuron, and the input is carried up to the thalamus and up to the cortex(28). In this study, nociceptive stimuli were applied to the spinal nervous system (hands) to exclude potential confounding from peripheral sensitization and to assess CS more directly. In many studies, such as the Orofacial Pain: Prospective Evaluation and Risk Assessment (OPPERA)(29), nociceptive stimuli were also applied to the spinally innervated areas in TMD patients.

1. TSSP in healthy volunteers with no pain

Generalized Linear Mixed Models to test TSSP response patterns at each stimulus intensity revealed that TSSP decreased significantly at PT ${ }^{\circ} \mathrm{C}$ and that TSSP did not increase significantly at PT $+1{ }^{\circ} \mathrm{C}$ and PT $+2{ }^{\circ} \mathrm{C}$. Besides, TSm and TSf at PT $+2{ }^{\circ} \mathrm{C}$ increased significantly more than those at PT $+1{ }^{\circ} \mathrm{C}$. This suggests that measuring TSSP at suprathreshold intensity $\left(\mathrm{PT}+2{ }^{\circ} \mathrm{C}\right)$ could avoid floor effects.

\section{TSSP in chronic pain patients}

Generalized Linear Mixed Models to test TSSP response patterns at each stimulus intensity revealed that TSSP did not increase significantly at PT ${ }^{\circ} \mathrm{C}$. Also, TSSP increased significantly at PT $+1{ }^{\circ} \mathrm{C}$ and PT +2 ${ }^{\circ} \mathrm{C}$. This finding demonstrated differences in TSSP response patterns between healthy volunteers with no pain and chronic pain patients at all stimulus intensities. Besides, there were significantly higher TSm and TSf in chronic pain patients at PT $+2{ }^{\circ} \mathrm{C}$. Overall this may indicate that the difference between chronic pain patients and healthy participants is observed only at suprathreshold intensity $\left(\mathrm{PT}+2{ }^{\circ} \mathrm{C}\right)$. The stimulus intensity should be individually adjusted to $2{ }^{\circ} \mathrm{C}$ above the patient's pain thresholds to assess TSSP clearly.

\section{Conclusions}

The difference between chronic pain patients and healthy participants with no pain was observed only at suprathreshold intensity (the pain threshold $+2{ }^{\circ} \mathrm{C}$ ). The stimulus intensity should be individually adjusted to $2{ }^{\circ} \mathrm{C}$ above the patient's pain thresholds to assess TSSP clearly.

\section{Limitations}

Notwithstanding the significant advantages of the present study, a few limitations also should be acknowledged and discussed. The main limitation could be significant differences in age between 
healthy volunteers and patients. A recent study reported that TSSP at longer interstimulus intervals (3.5sec and 4.5-sec) in middle-aged and older-aged groups was significantly higher compared to that in the younger-aged group. However, TSSP at an interstimulus interval of 2.5-sec in middle-aged and older-aged groups was not significantly higher than that in the younger-aged group(30). In this study, the interstimulus interval was set as 2-sec so that the interstimulus interval was shorter than 2.5-sec; however, age-matched controls identified should be identified in future studies.

In this study, nociceptive stimuli were only applied to the spinal nervous system to exclude the confounding from peripheral sensitization. However, there has been no evidence that the skin overlying the masseter of TMD pain patients presents peripheral sensitization. Future studies should be assessed through a stimulus applied to the muscle and not at the surface.

TSSP could be facilitated using various noxious stimuli, such as electrical, mechanical, and heat stimuli $(5,31)$. TSSP depends on spinal processes driven by the activation of C-fibers. Heat stimuli are suitable to rate second pain, particularly when participants are trained to rate the late sensation(30). It could activate A-delta and C-fibers, but more predominantly C-fibers(30). So, this study applied heat stimuli for dynamic QST. It is crucial for participants to rate the second pain evoked by C-fibers activation and not the first pain evoked by A-delta-fibers activation. However, there are equally valid and reliable techniques to measure temporal summation of pain in orofacial pain conditions(32), and it is not clear what is the advantage of the proposed one, in particular, because there is no comparator protocol.

\section{Abbreviations}

ANX: Anxiety

CS: Central sensitization

DEP: Depression

dynamic QST: Dynamic Quantitative Sensory Test

O-C: Obsessive-Compulsive

PCS: Pain Catastrophizing Scale

PI: Pain Intensity

PSEQ: Pain Self-Efficacy Questionnaire

PT: Pain thresholds

SCL-90R: Symptom Checklist-90-Revised

SOM: Somatization 
TSf: TSSP frequency

TSm: TSSP magnitude

TSSP: Temporal summation of second pain

VAS: Visual analog scale

\section{Declarations}

\section{Ethics approval and consent to participate}

The present research complied with the STROBE statement. This study was performed with the approval of the Osaka University Graduate School of Dentistry and the Ethics Review Committee of the Dental Hospital (H29-E43). Consent for participating in this study and publication was obtained from every patient.

\section{Consent for publication}

Not applicable.

\section{Availability of data and materials}

Further information on the data set and materials is available from the corresponding author upon reasonable request.

\section{Competing interests}

The authors declare that they have no competing interests.

\section{Funding}

This work was supported by JSPS KAKENHI Grant Number JP19K10204. The fund had no role in the data collection, analysis, interpretation, nor reporting of results.

\section{Authors' contributions \& Acknowledgements}

DM and SI have equally contributed to this work. DM and SI contributed to the conception and design of the study; DM, XL, and KK conducted the data acquisition; DM, RT, SI, and HY conducted interpretation of the data; DM, SI, and PS conducted data analysis; DM, SI, HY, and PS conducted manuscript drafting. All authors contributed to the critical revision of the article and approval of the final version.

\section{References}

1. IASP. Classification of Chronic Pain Seattle: IASP Press; 1994 [Second Edition:[ 
2. Gatchel RJ, Neblett R. Central Sensitization: A Brief Overview. Journal of Applied Biobehavioral Research. 2018;23(2).

3. Curatolo M. Central sensitization: Nice to know? European Journal of Pain. 2018;22(2):214-5.

4. Woolf CJ. Central sensitization: Implications for the diagnosis and treatment of pain. Pain. 2011;152(3):S2-S15.

5. Arendt-Nielsen L, Morlion B, Perrot S, Dahan A, Dickenson A, Kress HG, et al. Assessment and manifestation of central sensitisation across different chronic pain conditions. European Journal of Pain. 2018;22(2):216-41.

6. Rolke R, Baron R, Maier C, Tolle TR, Treede RD, Beyer A, et al. Quantitative sensory testing in the German Research Network on Neuropathic Pain (DFNS): Standardized protocol and reference values. Pain. 2006;123(3):231-43.

7. Maier C, Baron R, Tolle TR, Binder A, Birbaumer N, Birklein F, et al. Quantitative sensory testing in the German Research Network on Neuropathic Pain (DFNS): Somatosensory abnormalities in 1236 patients with different neuropathic pain syndromes. Pain. 2010;150(3):439-50.

8. Mackey IG, Dixon EA, Johnson K, Kong JT. Dynamic Quantitative Sensory Testing to Characterize Central Pain Processing. Jove-Journal of Visualized Experiments. 2017(120).

9. Marcuzzi A, Wrigley PJ, Dean CM, Adams R, Hush JM. The long-term reliability of static and dynamic quantitative sensory testing in healthy individuals. Pain. 2017;158(7):1217-23.

10. Vollert J, Attal N, Baron R, Freynhagen R, Haanpaa M, Hansson P, et al. Quantitative sensory testing using DFNS protocol in Europe: an evaluation of heterogeneity across multiple centers in patients with peripheral neuropathic pain and healthy subjects. Pain. 2016;157(3):750-8.

11. Harte SE, Harris RE, Clauw DJ. The neurobiology of central sensitization. Journal of Applied Biobehavioral Research. 2018;23(2).

12. Janal MN, Raphael KG, Cook DB, Sirois DA, Nemelivsky L, Staud R. Thermal temporal summation and decay of after-sensations in temporomandibular myofascial pain patients with and without comorbid fibromyalgia. Journal of Pain Research. 2016;9:641-52.

13. Kong JT, Johnson KA, Balise RR, Mackey S. Test-Retest Reliability of Thermal Temporal Summation Using an Individualized Protocol. Journal of Pain. 2013;14(1):79-88.

14. Zhou P, Li Y, Zhang JL, Chen YM, Wang KL, Svensson P. Temporal Summation of Painful Heat Stimulation Is Facilitated in Trigeminal and Extratrigeminal Regions in Painful Myofascial Temporomandibular Disorders: Evidence from a Case-Control Study. Journal of Oral \& Facial Pain and Headache. 2019;33(2):174-82.

15. Racine M, Tousignant-Laflamme Y, Kloda LA, Dion D, Dupuis G, Choiniere M. A systematic literature review of 10 years of research on sex/gender and experimental pain perception - Part 1: Are there really differences between women and men? Pain. 2012;153(3):602-18.

16. Racine M, Tousignant-Laflamme Y, Kloda LA, Dion D, Dupuis G, Choiniere M. A systematic literature review of 10 years of research on sex/gender and pain perception - Part 2: Do biopsychosocial factors alter pain sensitivity differently in women and men? Pain. 2012;153(3):619-35. 
17. El Tumi H, Johnson MI, Dantas PBF, Maynard MJ, Tashani OA. Age-related changes in pain sensitivity in healthy humans: A systematic review with meta-analysis. European Journal of Pain. 2017;21(6):955-64.

18. Hagander LG, Midani HA, Kuskowski MA, Parry GJG. Quantitative sensory testing: effect of site and skin temperature on thermal thresholds. Clinical Neurophysiology. 2000;111(1):17-22.

19. International Classification of Orofacial Pain, 1st edition (ICOP). Cephalalgia. 2020;40(2):129-221.

20. Schiffman E, Ohrbach R, Truelove E, Look J, Anderson G, Goulet JP, et al. Diagnostic Criteria for Temporomandibular Disorders (DC/TMD) for Clinical and Research Applications: Recommendations of the International RDC/TMD Consortium Network and Orofacial Pain Special Interest Group. Journal of Oral \& Facial Pain and Headache. 2014;28(1):6-27.

21. Kroenke K, Spitzer RL, Williams JBW. The PHQ-15: Validity of a new measure for evaluating the severity of somatic symptoms. Psychosomatic Medicine. 2002;64(2):258-66.

22. Gonzalez YM, Schiffman E, Gordon SM, Seago B, Truelove EL, Slade G, et al. Development of a brief and effective temporomandibular disorder pain screening questionnaire: reliability and validity. $\mathrm{J} \mathrm{Am}$ Dent Assoc. 2011;142(10):1183-91.

23. Sullivan M, Bishop S, Pivik J. The Pain Catastrophizing Scale: Development and validation. Psychological Assessment. 1995;7:524-32.

24. Nicholas MK. The pain self-efficacy questionnaire: Taking pain into account. European Journal of Pain. 2007;11(2):153-63.

25. Derogatis LR. Confirmation of the dimensional structure of the scl-90: A study in construct validation. Journal of Clinical Psychology. 1977;33(4):9.

26. Hardt J, Gerbershagen HU, Franke P. The symptom check-list, SCL-90-R: its use and characteristics in chronic pain patients. European Journal of Pain-London. 2000;4(2):137-48.

27. Mendell LM. Physiological properties of unmyelinated fiber projection to the spinal cord. Exp Neurol. 1966;16(3):316-32.

28. Okeson JP. Bell's Oral and Facial Pain. 2014.

29. Greenspan JD, Slade GD, Bair E, Dubner R, Fillingim RB, Ohrbach R, et al. Pain sensitivity risk factors for chronic TMD: descriptive data and empirically identified domains from the OPPERA case control study. J Pain. 2011;12(11 Suppl):T61-74.

30. Riley JL, Cruz-Almeida Y, Staud R, Fillingim RB. Effects of manipulating the interstimulus interval on heat-evoked temporal summation of second pain across the age span. Pain. 2019;160(1):95-101.

31. Kong JT, Schnyer RN, Johnson KA, Mackey S. Understanding Central Mechanisms of Acupuncture Analgesia Using Dynamic Quantitative Sensory Testing: A Review. Evidence-Based Complementary and Alternative Medicine. 2013.

32. Moana-Filho EJ, Herrero Babiloni A, Theis-Mahon NR. Endogenous pain modulation in chronic orofacial pain: a systematic review and meta-analysis. Pain. 2018;159(8):1441-55. 
Figures

\section{Figure 1}

Flow diagram of participants.

(a) healthy volunteers with no pain, (b) chronic pain patients.

\section{3}

\section{5}

$\overbrace{\substack{ \pm 0}}^{2} 1.5$

0.5

0

2

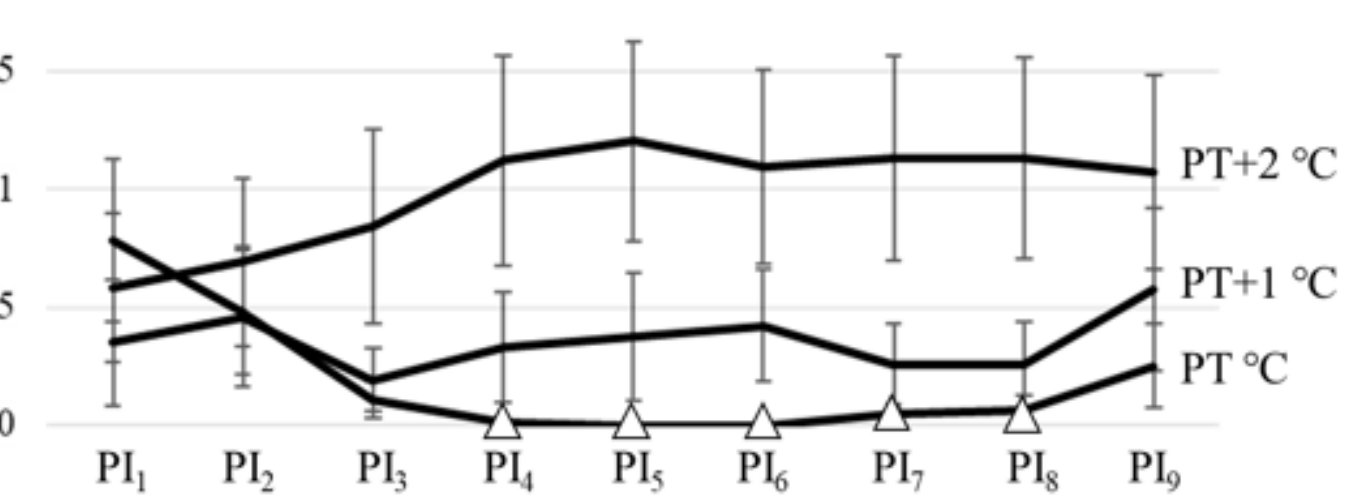

Significant level of $\mathrm{PI}_{\mathrm{a}}-\mathrm{PI}_{1}$

\begin{tabular}{lcccccccc}
\hline & $\mathrm{PI}_{2}$ & $\mathrm{PI}_{3}$ & $\mathrm{PI}_{4}$ & $\mathrm{PI}_{5}$ & $\mathrm{PI}_{6}$ & $\mathrm{PI}_{7}$ & $\mathrm{PI}_{8}$ & $\mathrm{PI}_{9}$ \\
\hline $\mathrm{PT}{ }^{\circ} \mathrm{C}$ & .487 & .059 & .027 & .026 & .026 & .037 & .044 & .175 \\
$\mathrm{PT}+1{ }^{\circ} \mathrm{C}$ & .790 & .596 & .951 & .949 & .844 & .764 & .765 & .605 \\
$\mathrm{PT}+2{ }^{\circ} \mathrm{C}$ & .819 & .615 & .326 & .241 & .328 & .310 & .302 & .348 \\
\hline
\end{tabular}

\section{Figure 2}

TSSP response patterns in healthy volunteers with no pain (women only: $n=15$ ). showed that $\mathrm{PI}_{n}$ was significantly lower than $\mathrm{PI}_{1}$. Pain Intensity $\left(\mathrm{PI}_{n}\right)$ was calculated by integrating the values of pain ratings from the peak of the temperature at the $n^{\text {th }}$ stimulus to the peak of the temperature at the $n+1^{\text {th }}$ stimulus. 


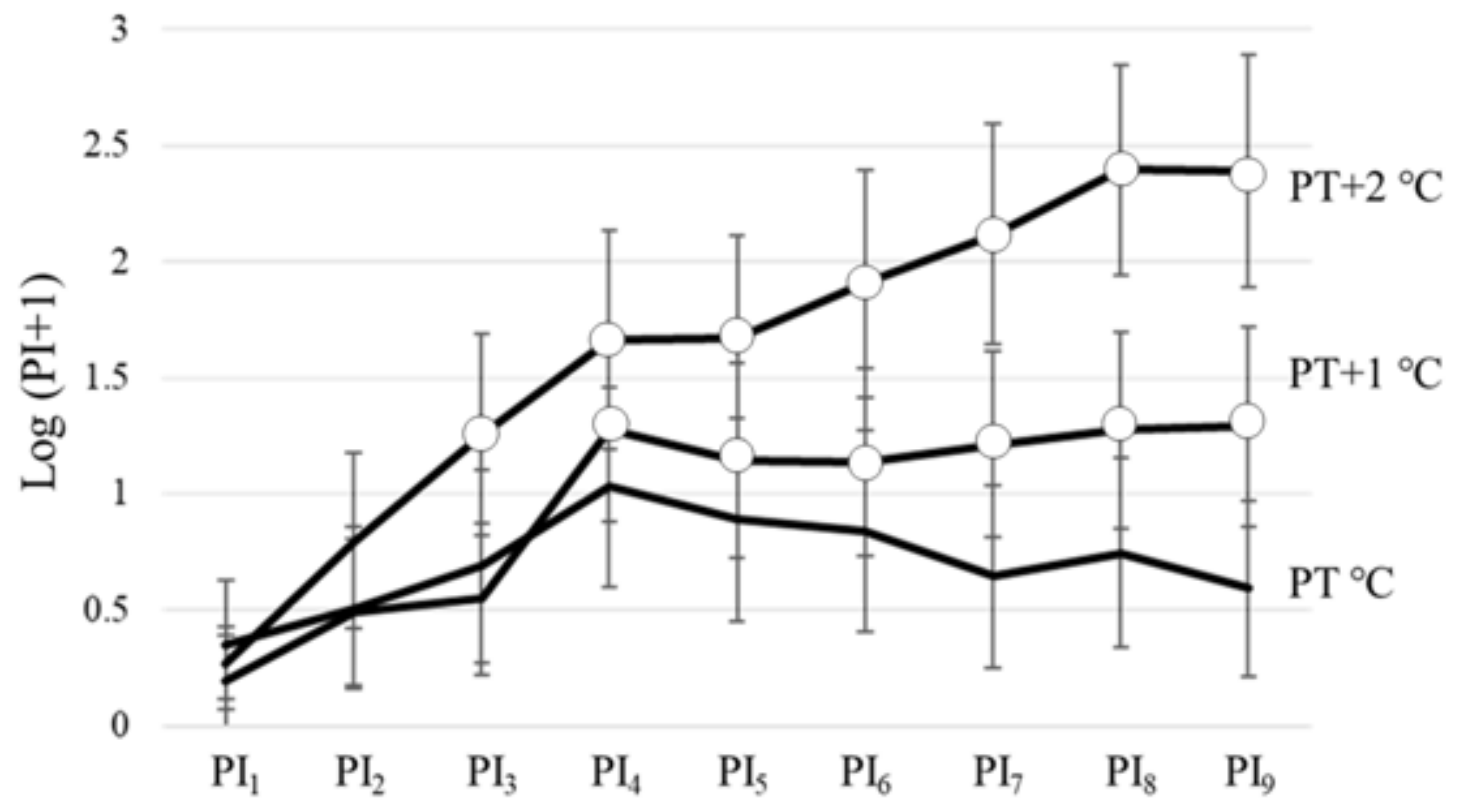

Significant level of $\mathrm{PI}_{\mathrm{m}}-\mathrm{PI}_{1}$

\begin{tabular}{lcccccccl}
\hline & $\mathrm{PI}_{2}$ & $\mathrm{PI}_{3}$ & $\mathrm{PL}_{4}$ & $\mathrm{PI}_{5}$ & $\mathrm{PI}_{6}$ & $\mathrm{PI}_{7}$ & $\mathrm{PI}_{8}$ & \multicolumn{1}{c}{$\mathrm{PI}_{9}$} \\
\hline $\mathrm{PT}{ }^{\circ} \mathrm{C}$ & .72 & .50 & .19 & .30 & .35 & .55 & .43 & .61 \\
$\mathrm{PT}+1{ }^{\circ} \mathrm{C}$ & .42 & .35 & .016 & .041 & .038 & .024 & .022 & .022 \\
$\mathrm{PT}+2{ }^{\circ} \mathrm{C}$ & .20 & .035 & .006 & .003 & .002 & $<.001$ & $<.001$ & $<.001$ \\
\hline
\end{tabular}

Figure 3

TSSP response patterns in chronic pain patients (women only; $n=16$ ). showed that $\mathrm{PI}_{n}$ was significantly higher than $\mathrm{PI}_{1}$. Pain Intensity $\left(\mathrm{PI}_{n}\right)$ was calculated by integrating the values of pain ratings from the peak of the temperature at the nth stimulus to the peak of the temperature at the $n+1$ th stimulus.

\section{Supplementary Files}

This is a list of supplementary files associated with this preprint. Click to download.

- chronicpainpatients.zip

- controls.zip 